\section{Pergamon Publications}

\section{Problems in}

\section{Mathematical Physics}

\section{N. N. Lebedev, et ol.}

This collection is intended for post-graduate students taking courses in mathematical physics. The subjects covered include several branches of mechanics, theory of heat conduction, and theory of electric and magnetic phenomena.

Contents: Derivation of equations and the statement of problems in mathematical physics; Some special methods of investigating differential equations of hyperbolic and elliptic type;

Steady-state periodic vibrations; Fourier's method; The method of eigenfunctions applied to inhomogeneous problems of mathematical physics; Problems of mathematical physics with a continuous spectrum; Integral transformations; The method of curvilinear co-ordinates; Integral equations.

416 pages. 1966. $63 \mathrm{~s}$.

\section{The Monte Carlo Method}

\section{Edited by Yu. A. Shreider, Moscow Academy of Sciences}

This book describes the method of statistical trials, or the simulation of random processes on digital computers, and deals with the application of the theory to neutron physics, the communication theory and the theory of servicing systems.

Contents: Principles of the Monte Carlo method: Computation of definite integrals; Application of the Monte Carlo method to neutron physics; Application to the investigation of servicing processes; Application to the communication theory; Generation of uniformly distributed random variables on electronic computers; Transformation of random numbers.

384 pages. 1966.80 s.

\section{The Theory of Finitely Generated Commutative Semigroups}

\section{Redei}

A concise exposition of the author's work on finitely generated commutative semigroups, founded on a single fundamental theorem and developed in a sequence of "finiteness theorems". Many examples illustrating the theory are given with the aim of stimulating the reader to further research.

Contents: Kernel functions and fundamental theorem: Elementary properties of the kernel functions; Ideal theory of free semimodules of finite rank; Further properties of the kernel functions; Equivalent kernel functions.

368 pages. 1965. $84 \mathrm{~s}$.

\section{Topology}

An International Journal of Mathematics founded by J. H. C. Whitehead, Oxford

Editors: M. F. Atiyah, R. Bott, F. Hirzebruch, I. M. James, and R. Thom

This journal publishes papers in mathematics with special emphasis on topology and related subjects and the use of topological techniques such as homological algebra, Lie groups, differential geometry and algebraic geometry. Published twice monthly.

For a specimen copy and details of subscription rates please write to:

Subscription Manoger, Pergamon Press Ltd., Headington Hill Hall, Oxford

\section{PERGAMON PRESS}

Headington Hill Hall, Oxford 


\title{
Proceedings of the Glasgow Mathematical Association
}

\author{
Editorial Committee: R. A. Rankin, R. P. Gillespie, T. S. Graham, A. Geddes \\ Department of Mathematics, The University, Glasgow \\ Volume 7. Part 3 January 1966
}

T. B. J. T. ALLENBY. Adjunction of roots to nilpoint groups.

I. J. MADDOX. Generalized Cesaro means of order-1.

K. N. SRIVASTAVA. On integral equations involving Whittaker's function.

R. E. PEINADO AND W. G. LEAVITT. The maxit and minit of a ring.

I. N. SNEDDON. The Reissner-Sagosi problem.

J. M. HOWIE AND G. LALLEMENT. Certain fundamental congruences on a regular

N. R. REILLY. Bisimple $w$-semigroups. semigroup.

R. A. RANKIN. Isomorphic congruence groups and hecke operators.

The proceedings are published twice yearly, four parts comprising a volume of about 200 pages. The subscription price per volume is $£ 3(\$ 10.00)$, post free, payable in advance. Single parts may be supplied at a cost of $15 s$. (\$2.50) net.

Inquiries and subscription orders should be sent to the publishers

OLIVER and BOYD LTD., Tweeddale Court, 14 High Street, Edinburgh, 1

\section{STATISTICAL THEORY AND METHOD ABSTRACTS}

\section{A Journal of the International Statistical Institute}

The object of this abstracting service is to cover published papers concerned with statistical theory, including relevant aspects of probability and mathematical methods, and new contributions to statistical method. These abstracts provide valuable information on new developments for studying problems in many fields; for example, reliability, quality control, experiments, surveys, queueing, congestion and forecasting. Approximately 500 journals are scanned for suitable papers. Abstracts are also prepared from collections of papers such as reports of conferences, symposia and seminars: technical reports of experiment and research stations are covered.

Approximately 400 words long, these literary informative abstracts are written in English; the language of the original paper is indicated. The heading not only gives the name and address of the author together with the journal in which the paper was published, but a note is given of references, tables, etc.

The revised classification scheme consists of three parts. The pages of the journal are colour-tinted in groups to provide visual indication of twelve main sections. Each section is further sub-divided to indicate the main topic of the paper; a secondary number denotes the most important additional topic referred to by the author. A special table in each part links together these two classifications. This scheme is arranged to facilitate transfer to punch cards. When papers are concerned with new statistical tables the relevant classification for the Greenwood/Hartley Guide (1962) is indicated in a special section.

The abstracts are numbered serially, the volume number being inserted as a prefix. The journal is published four times a year and contains approximately 1,250 abstracts. Relevant indexes are published in each issue and combined in a yearly supplement.

$\begin{array}{ll}\text { Annual Subscription } & £ 7,10 \mathrm{~s} \text {. (U.S.A. } \$ 24.00) \\ \text { Single Number } & £ 2,5 \mathrm{~s} \text {. (U.S.A. } \$ 7.00) \\ \text { Loose Leaf Binders for Single } & 16 \mathrm{~s} \text {. 3d. including postage } \\ \text { Abstract Sheets } & \text { and packing. }\end{array}$

OLIVER AND BOYD LTD. Tweeddale Court, 14 High Street, Edinburgh, 1 